\title{
INGESTÃO PROLONGADA DE CHÁ BRANCO NOS PARÂMETROS HEMATOLÓGICOS DE RATAS WISTAR
}

Deyvid Parreira Vieira', Samuel Aparecido Freire', Cyntia dos Santos Monteiro', Érica Solange Caetano Kikuchi', Aline de Oliveira Santos', Caliê Castilho', Cecília Braga Laposy', Rosa Maria Barilli Nogueira', Luciana Machado Guaberto ', Rogério Giuffrida', Lilian Francisco de Souza', Ines Cristina Giometti'

${ }^{1}$ Universidade do Oeste Paulista - UNOESTE, Medicina Veterinária, Presidente Prudente, SP. E-mail: inesgiometti@unoeste.br

\section{RESUMO}

O chá branco é uma bebida saudável, porém esse chá pode interferir em vários fatores de crescimento envolvidos no metabolismo. Portanto, este trabalho teve como objetivo verificar o efeito do consumo prolongado de chá branco nos parâmetros hematológicos de ratas Wistar. Foram utilizados dois grupos de ratas: controle $(n=30)$ que recebeu água e o grupo que recebeu apenas chá branco para beber $(n=30)$. 0 experimento teve duração de 3 meses, ao final de cada mês, 10 ratas de cada grupo eram eutanasiadas e o sangue dos animais colhido para hemograma e bioquímica sérica. A análise estatística foi a ANOVA seguida do teste de Tukey e Teste $T$, foram consideradas diferenças estatísticas quando $P<0,05$. Não houve diferença estatística entre os grupos na contagem de células sanguíneas. Conclui-se que o chá branco não interfere nos parâmetros hematológicos de ratas Wistar.

Palavras-chave: Camellia sinensis; catequina; hemograma; leucograma; contagem de células sanguíneas.

\section{CHRONIC INGESTION OF WHITE TEA IN THE HAEMATOLOGICAL PARAMETERS OF WISTAR RATS}

\begin{abstract}
The white tea in a healthy drink, but this tea can interfere in some growth factors involved in the metabolism. Therefore, the aim of this work was to verify the effect of the white tea chronic ingestion in the haematological parameters of female Wistar rats. There were utilized two groups of rats: control $(n=30)$ that received water and the group that received only white tea to drink $(n=30)$. The experiment lasts three months and in the end of each month, 10 rats of each group were euthanized and the blood of animals was collected for cell blood count. The statistical analysis was ANOVA tests followed of Tukey analysis and $T$ tests, differences were consider when $P<0.05$. No one statistical difference was observed between the groups in the blood cell count. The conclusion is the white tea does not interfere in the haematological parameters of Wistar rats.
\end{abstract}

Keywords: Camellia sinensis; catechin; hemogram; leukogram; blood cell count.

\section{REVISÃO DE LITERATURA}

A planta Camellia sinensis é utilizada para a fabricação de diferentes tipos de chás, dependendo da forma como são produzidos, como o chá branco, verde e preto, que diferem no conteúdo de flavonoides, responsáveis pela sua atividade fisiológica (ANGER et al., 2005). Esses flavonoides, como as catequinas, polifenois e outros, auxiliam em inúmeros mecanismos que podem proporcionar efeitos benéficos ao organismo (JENNY et al., 2010). Dentre os principais benefícios do consumo desses chás, pode-se citar a prevenção ao câncer, doenças cardiovasculares e osteoporose (LIAO et al., 2001; HIGDON; FREI, 2003).

O chá branco, que é parecido com o chá verde na sua composição de catequinas, é minimamente processado, a partir de botões e folhas jovens da Camellia sinensis, sendo colhido somente durante o início da primavera, antes dos botões serem completamente abertos, e por isso, possuem mais altas concentrações de 
catequinas que o chá verde, que é preparado de folhas maduras (HILAL; ENGELHARDT 2007). Porém, quase não existem estudos na literatura sobre o chá branco.

As principais catequinas presentes nesses chás, epicatequina (EC), epicatequina galato (ECG), epigalocatequina (EGC) e epigalocatequina galato (EGCGG), têm efeitos múltiplos na proteção do organismo, anti-inflamatório, antihipertensivo, antitrombótico, antioxidativo, antiproliferativo, antibacteriano e de amplo espectro e também têm efeitos na perda lipídica (BALENTINE et al., 1997; ARAKAWA et al., 2004; BHATT et al., 2010), por meio da inibição de enzimas da biossíntese de lipídeos e da redução da absorção intestinal (HIGDON; FREI, 2003).

Foi demonstrado que essas catequinas previnem $o$ aparecimento de placas aterioscleróticas em vários modelos de hiperlipidemia (KHAN et al., 1992; MIURA et al., 2001) e também reduzem o nível de colesterol do sangue e em tecidos como fígado e coração de ratos hipercolesterolêmicos (YANG; KOO, 1997; BABU et al., 2006; TEIXEIRA et al., 2012).

Devido a importância as catequinas presentes no chá branco para a saúde, e como pouco se conhece sobre o efeito da ingestão do chá branco sobre as células sanguíneas do organismo saudável, já que o chá será metabolizado e as catequinas não são os únicos componentes presentes no chá branco, o objetivo do presente trabalho é verificar a influência do consumo diário prolongado de chá branco no leucograma e hemograma de ratas Wistar.

\section{METODOLOGIA}

O experimento foi aprovado pelo Comitê de Ética no Uso de Animais (protocolo CEUA número 336/10). Foram utilizadas 60 ratas Wistar, em idade reprodutiva (11 semanas), peso médio de $150 \mathrm{~g}$, nulíparas, divididas em dois grupos com 30 animais cada, provenientes do Biotério Central da UNOESTE. As ratas foram pesadas, identificadas e então, mantidas em caixas tamanho padrão utilizadas no biotério, contendo 5 animais por caixa, com maravalha, bebedouro e comedouro com ração (Supralab", Raça Forte). Um grupo recebeu água ad libitum no bebedouro e o outro, somente chá branco para beber, em uma situação experimental de ingestão prolongada como realizado por Yang et al. (2003) e Niwattisaiwong et al. (2004). O chá foi preparado em uma concentração de 2,5\% pela adição de água fervente no extrato puro de chá branco e então filtrado.

O tratamento com chá teve duração total de 3 meses, ao final de 30 dias, 10 ratas de cada grupo (controle e tratadas) foram anestesiadas com éter, e sacrificadas por exsanguinação. 0 sangue foi colhido por punção cardíaca e utilizado para realizar hemograma e bioquímica sérica.

Utilizou-se tubos a vácuo com $10 \%$ de EDTA, com uso de contador automático (SysmexRoche Sysmex, Brasil). A contagem diferencial de leucócitos foi feita por meio de esfregaço sanguíneo corado por coloração rápida (DiffQuick), segundo Jain (1993). Quantificou-se o fibrinogênio plasmático utilizando a técnica de precipitação pelo calor preconizado por Kaneko et al. (2008). As proteínas plasmáticas foram mensuradas por refratometria. O colesterol total, triglicerídeos e glicose foram determinados com a utilização de kits bioquímicos (Labtest ${ }^{\circ}$ ) e analisador semi-automático (Quick-Lab-Drake).

Todos os grupos de dados foram testados quanto ao pressuposto de normalidade empregando-se o teste de Kolmogorv-Smirnov pelo qual foram consideradas como variáveis de distribuição gaussiana aquelas que resultaram em significância $>0,10$. Para comparar os parâmetros das ratas mensurados nos diferentes momentos para os grupos controle e tratado empregou-se o teste de análise de variância para dados pareados (ANOVA), com contrastes pelo método de Tukey-Kramer. Para comparar os valores médios dos parâmetros analisados entre os grupos controle e experimental empregou-se o teste $\mathrm{t}$ não pareado. Diferenças estatísticas significativas foram consideradas quando $\mathrm{P}<0,05$.

Para os parâmetros que não tiveram uma distribuição normal (fibrinogênio), a análise utilizada foi não paramétrica (teste de KruskalWallis) entre os momentos de cada grupo e o teste de Mann-Whitney para comparar os grupos em cada momento.

\section{RESULTADOS}

A tabela 1 mostra as médias e os desvios padrões do hemograma das ratas do grupo controle e tratado com chá branco aos 30,60 e 90 dias. Aos 30 dias de experimento observou-se no grupo controle maior número de hemácias, maior hematócrito, maior CHCM (Concentração de Hemoglobina Corpuscular Média) e menor 
HCM (Hemoglobina Corpuscular Média) que o grupo tratado. Aos 60 dias verificou-se diferença significativa entre os grupos somente no valor de VCM (Volume Corpuscular Médio) que foi maior no grupo controle. Aos 90 dias não houve diferença entre os grupos para nenhum dos parâmetros do hemograma. Houve aumento do número de eritrócitos no grupo tratado com chá branco no segundo mês de experimento e diminuição do HCM do grupo tratado no terceiro mês de experimento comparado com o primeiro mês $(p<0,05)$.

Tabela 1. Médias e desvios-padrões dos parâmetros analisados no eritrograma de ratas $(n=10)$ tratadas com água, grupo controle (CT) e chá branco (CB) aos 30, 60 e 90 dias.

\begin{tabular}{|c|c|c|c|c|}
\hline \multirow[t]{2}{*}{ Parâmetro } & \multirow[t]{2}{*}{ Grupo } & \multicolumn{3}{|c|}{ Momentos (dias) } \\
\hline & & 30 & 60 & 90 \\
\hline \multirow{2}{*}{$\begin{array}{l}\text { Eritrócitos } \\
\left(10^{6} / \mathrm{mm}^{3}\right)\end{array}$} & CT & $8,37 \pm 0,21^{\mathrm{Aa}}$ & $7,84 \pm 0,90^{\mathrm{Aa}}$ & $8,33 \pm 0,76^{\mathrm{Aa}}$ \\
\hline & CB & $7,72 \pm 0,56^{\mathrm{Ba}}$ & $8,34 \pm 0,46^{\mathrm{Ab}}$ & $8,10 \pm 0,39^{\text {Aab }}$ \\
\hline \multirow{2}{*}{$\begin{array}{c}\text { Hemoglobina } \\
(\mathrm{g} / \mathrm{dL})\end{array}$} & CT & $16,19 \pm 0,35^{\mathrm{Aa}}$ & $15,55 \pm 1,76^{\mathrm{Aa}}$ & $16,26 \pm 1,70^{\mathrm{Aa}}$ \\
\hline & CB & $15,40 \pm 1,23^{\mathrm{Aa}}$ & $16,24 \pm 0,79^{\mathrm{Aa}}$ & $15,59 \pm 0,59^{\mathrm{Aa}}$ \\
\hline \multirow{2}{*}{$\begin{array}{l}\text { Hematócrito } \\
\text { (\%) }\end{array}$} & CT & $45,48 \pm 1,43^{\mathrm{Aa}}$ & $43,53 \pm 4,63^{\mathrm{Aa}}$ & $45,81 \pm 4,99^{\mathrm{Aa}}$ \\
\hline & CB & $42,31 \pm 3,02^{\mathrm{Ba}}$ & $45,06 \pm 2,26^{\mathrm{Aa}}$ & $43,68 \pm 1,71^{\mathrm{Aa}}$ \\
\hline \multirow{2}{*}{$\begin{array}{l}\text { VCM } \\
\text { (fL) }\end{array}$} & CT & $54,69 \pm 1,68^{\mathrm{Aa}}$ & $55,63 \pm 1,48^{\mathrm{Aa}}$ & $54,96 \pm 1,34^{\mathrm{Aa}}$ \\
\hline & $\overline{C B}$ & $54,85 \pm 0,79^{\text {Aa }}$ & $54,08 \pm 0,89^{\mathrm{Ba}}$ & $53,98 \pm 1,31^{\mathrm{Aa}}$ \\
\hline \multirow{2}{*}{$\begin{array}{l}\text { HCM } \\
\text { (pg) }\end{array}$} & $\mathrm{CT}$ & $19,35 \pm 0,43^{\mathrm{Aa}}$ & $19,85 \pm 0,47^{\mathrm{Aa}}$ & $19,50 \pm 0,46^{\mathrm{Aa}}$ \\
\hline & CB & $19,96 \pm 0,40^{\mathrm{Ba}}$ & $19,50 \pm 0,41^{\text {Aab }}$ & $19,27 \pm 0,61^{\mathrm{Ab}}$ \\
\hline \multirow{2}{*}{$\begin{array}{c}\mathrm{CHCM} \\
(\%)\end{array}$} & CT & $35,63 \pm 0,61^{\mathrm{Aa}}$ & $35,70 \pm 0,76^{\mathrm{Aa}}$ & $35,51 \pm 0,40^{\mathrm{Aa}}$ \\
\hline & $\overline{C B}$ & $36,36 \pm 0,36^{\mathrm{Ba}}$ & $36,06 \pm 0,53^{\mathrm{Aa}}$ & $35,70 \pm 0,69^{\mathrm{Aa}}$ \\
\hline \multirow{2}{*}{$\begin{array}{c}\text { PPT } \\
\text { (g/dL) }\end{array}$} & CT & $6,98 \pm 0,33^{\mathrm{Aa}}$ & $7,00 \pm 0,37^{\mathrm{Aa}}$ & $6,93 \pm 0,44^{\mathrm{Aa}}$ \\
\hline & CB & $7,03 \pm 0,59^{\mathrm{Aa}}$ & $6,89 \pm 0,36^{\mathrm{Aa}}$ & $7,02 \pm 0,29^{\mathrm{Aa}}$ \\
\hline \multirow{2}{*}{$\begin{array}{c}\text { Fibrinogênio } \\
\text { (mg/dL) }\end{array}$} & $\mathrm{CT}$ & $200,00 \pm 0,00^{A a}$ & $250,00 \pm 92,58^{\mathrm{Aa}}$ & $222,22 \pm 66,67^{\mathrm{Aa}}$ \\
\hline & CB & $275,00 \pm 103,51^{\mathrm{Aa}}$ & $222,22 \pm 66,67^{\mathrm{Aa}}$ & $311,11 \pm 105,41^{\mathrm{Aa}}$ \\
\hline
\end{tabular}

VCM, corpuscular médio; HCM, hemoglobina corpuscular média; CHCM, concentração de hemoglobina corpuscular média; PPT, proteína plasmática total. Valores na mesma coluna seguidos de letras maiúsculas iguais e valores na mesma linha seguidos de letras minúsculas iguais não diferem estatisticamente $(p>0,05)$.

Quando foi avaliado o leucograma dos animais (tabela 2), observou-se aumento significativo $(P<0,05)$ no número de neutrófilos segmentados e de monócitos no grupo tratado com chá branco durante o experimento, porém esse grupo não diferiu $(P>0,05)$ grupo controle em nenhum dos momentos avaliados. 
Tabela 2. Médias e desvios-padrões dos parâmetros avaliados no leucograma de ratas $(n=10)$ tratadas com água, grupo controle (CT) e chá branco (CB) aos 30, 60 e 90 dias.

\begin{tabular}{|c|c|c|c|c|}
\hline \multirow[t]{2}{*}{ Parâmetro } & \multirow[t]{2}{*}{ Grupo } & \multicolumn{3}{|c|}{ Momentos (dias) } \\
\hline & & 30 & 60 & 90 \\
\hline \multirow{2}{*}{$\begin{array}{c}\text { Leucócitos } \\
\text { (células } / \mathrm{mm}^{3} \text { ) }\end{array}$} & CT & $6.512,5 \pm 2.692,5^{\mathrm{Aa}}$ & $5.937,5 \pm 3.046,7^{\mathrm{Aa}}$ & $6.888,9 \pm 2.713,6^{\mathrm{Aa}}$ \\
\hline & CB & $5.787,5 \pm 1.345,3^{\mathrm{Aa}}$ & $7.511,1 \pm 2.869,0^{\mathrm{Aa}}$ & $8.244,4 \pm 2.659,0^{\mathrm{Aa}}$ \\
\hline \multirow{2}{*}{$\begin{array}{l}\text { Segmentados } \\
\text { (células/mm } / \mathrm{mm}^{3} \text { ) }\end{array}$} & CT & $1.104,4 \pm 828,4^{\mathrm{Aa}}$ & $1.255,3 \pm 769,3^{\mathrm{Aa}}$ & $1.753,4 \pm 545,4^{\mathrm{Aa}}$ \\
\hline & CB & $886,8 \pm 367,6^{\mathrm{Aa}}$ & $1.650,8 \pm 856,2^{\mathrm{Aab}}$ & $2.248,7 \pm 1.116,1^{\mathrm{Ab}}$ \\
\hline \multirow{2}{*}{$\begin{array}{c}\text { Eosinófilos } \\
\text { (células } / \mathrm{mm}^{3} \text { ) }\end{array}$} & CT & $220,4 \pm 223,6^{\mathrm{Aa}}$ & $213,4 \pm 226,2^{\mathrm{Aa}}$ & $231,3 \pm 208,5^{\mathrm{Aa}}$ \\
\hline & CB & $113,9 \pm 143,3^{\mathrm{Aa}}$ & $210,4 \pm 169,1^{\mathrm{Aa}}$ & $269,1 \pm 204,2^{\mathrm{Aa}}$ \\
\hline \multirow{2}{*}{$\begin{array}{c}\text { Linfócitos } \\
\text { (células } / \mathrm{mm}^{3} \text { ) }\end{array}$} & CT & $4.968,8 \pm 1.764,5^{\mathrm{Aa}}$ & $4.277,4 \pm 2.056,2^{\mathrm{Aa}}$ & $4.636,4 \pm 2.128,0^{\mathrm{Aa}}$ \\
\hline & CB & $4.644,0 \pm 1.030,3^{\mathrm{Aa}}$ & $5.483,3 \pm 1.978,3^{\mathrm{Aa}}$ & $5.387,2 \pm 1.635,6^{\mathrm{Aa}}$ \\
\hline \multirow{2}{*}{$\begin{array}{c}\text { Monócitos } \\
\text { (células } / \mathrm{mm}^{3} \text { ) }\end{array}$} & CT & $219,0 \pm 212,1^{\mathrm{Aa}}$ & $179,4 \pm 195,9^{\mathrm{Aa}}$ & $262,4 \pm 188,4^{\mathrm{Aa}}$ \\
\hline & CB & $135,0 \pm 94,8^{\mathrm{Aa}}$ & $156,1 \pm 108,9^{\mathrm{Aa}}$ & $339,4 \pm 154,6^{\mathrm{Ab}}$ \\
\hline
\end{tabular}

Valores na mesma coluna seguidos de letras maiúsculas iguais e valores na mesma linha seguidos de letras minúsculas iguais não diferem estatisticamente $(p>0,05)$.

\section{DISCUSSÃO}

Apesar de haver diferença significativa entre o grupo controle e tratado no número de eritrócitos, os valores de ambos os grupos estão dentro dos valores de referência do biotério da UNOESTE que vão de $5,43 \times 10^{6} / \mathrm{mm}^{3}$ a $10,43 \times 10^{6} / \mathrm{mm}^{3}$ (dados não publicados), e, portanto, não deve ter significado clínico. 0 hematócrito apresentou uma diferença significativa entre os grupos no primeiro mês de experimento, provavelmente devido ao menor número de hemácias, porém, também está dentro dos valores de referência de 32 a 52\%. Também estão dentro dos valores de referência o VCM, HCM e VHCM, e, portanto, não devem ter significado clínico.

Mesmo o grupo tratado com chá branco apresentando um aumento no número de neutrófilos segmentados e de monócitos no decorrer do experimento, não houve diferença no número de células brancas entre os grupos. Em trabalho com pacientes com células de pacientes saudáveis e pacientes com leucemia, o extrato da raiz da planta Camellia sinensis foi capaz de diminuir a contagem das células brancas dos pacientes com leucemia, mas não causou qualquer diminuição ou citotoxicidade nas de paciente saudáveis (GHOSH et al., 2006). Ao contrário dos resultados do presente com chá branco, o tratamento com chá verde levou a um maior número de células de defesa em ratos (GIOMETTI et al., 2011) e suínos (HOSSAIN et al., 2012). Segundo Cabrera et al. (2006), o chá verde fortalece a ação do sistema imune porque protege o organismo contra oxidantes e radicais livres.

\section{CONCLUSÃO}

Conclui-se que o chá branco não interfere nos parâmetros hematológicos de ratas Wistar.

\section{AGRADECIMENTOS}

Ao apoio financeiro da FAPESP (processo número 2010/20100-1) e UNOESTE.

\section{REFERÊNCIAS}

ANGER, D.L.; PETRE, M.A.; CRANKSHAW, D.J. Heteroactivation of cytochrome P450 1A1 by teas and tea polyphenols. British Journal of Pharmacology, v.145, p.926-933, 2005. https://doi.org/10.1038/sj.bjp.0706255

ARAKAWA, H.; MAEDA, M.; OKUBO, S.; SHIMAMURA T. Role of hydrogen peroxide in bactericidal action of catechin. Biol. Pharm. Bull., v.27, n.3, p.277-281, 2004. https://doi.org/10.1248/bpb.27.277

BABU, P.V.A.; SABITHA, K.E.; SHYAMALADEVI, C.S. Green tea extract impedes dyslipidaemia and development of cardic dysfunction in streptozotocin-diabetic rats. Clin. Exp. Pharmacol. Physiol., v.33, p.1184-1189, 2006. https://doi.org/10.1111/j.1440-

1681.2006.04509.x

BALENTINE, D.A.; WISEMAN, S.A.; BOUWENS, L. The chemistry of tea flavonoids. Rev Food Sci Nutr, v.37, p.693-704, 1997. https://doi.org/10.1080/10408399709527797 BHATT, P.R.; PANDYA, K.B.; SHETH; N.R. Camellia sinensis (I): the medicinal beverage: a review. 
International Journal of Pharmaceutical Sciences Review and Research, v.3, n.2, p.6-9, 2010. CABRERA, C.; ARTACHO, R.; GIMENEZ, R. Beneficial Effects of Green Tea. A Review Journal of the American College of Nutrition, v.25, p.7999, 2006. https://doi.org/10.1080/07315724.2006.107195 18

GHOSH, P.; BESRA, S.E.; TRIPATHI, G.; MITRA, S.; VEDASIROMONI, J.R. Cytotoxic and apoptogenic effect of tea root extrat and two of its steroidal Saponin of TS1 and TS2 on human leukemic cell lines K562 and U937 and on cell of CML and all patients. Leuk Res, v.30, n.4, p.459-468, 2006. https://doi.org/10.1016/j.leukres.2005.08.018 GIOMETTI, I.C.; PAPA, P.C.; CASTILHO, C.; LAPOSY, C.B.; ZANFOLIN, L.R.L.; DONADELI, J.P.P.; SANTOS, C.M. Influência do chá verde proveniente da erva Camellia sinensis no leucograma de ratas Wistar. Colloquium Agrariae, p.7, v.261-261, 2011.

HIGDON, J.V.; FREI, B. Tea catechins and polyphenols: health effects, metabolism, and antioxidant functions. Crit. Rev.Food Sci. Nutr., v.43, p.89-143, 2003. https://doi.org/10.1080/10408690390826464

HILAL, Y.; ENGELHARDT, U. Characterization of white tea - comparison to green and black tea. J. Vergbr., v. 2, p. 414-421, 2007.

HOSSAIN, M.E.; KO, S.Y; YANG, C.J. Dietary supplementation of green tea by-products on growth performance, meat quality, blood parameters and immunity in finishing pigs. Journal of Medicinal Plants Research, v. 6, n.12, p.2458-2467, 2012.

JAIN, N.C. Essentials of Veterinary Hematology. 1. ed. Philadelphia: Lea \& Febiger, 1993.

JENNY, T. MAO.; WEN-XIAN. NIE.; I-HSIEN, TSU.; YU-SHENG, JIN.; JIAN, YU RAO.; QING-Y, LU.; ZUOFENG, ZHANG.; VAY, LIANG W. GO.; KENNTH, J. SRIO. White Tea Extract Induces Apoptosis in Nonsmall Cell Lung Cancer Cells- The Role of PPAR- $\gamma$ and 15-Lipoxygenases. Cancer Prev Res. p, 1132-1140, 2010.

KANEKO, J.J.; HARVEY, J.W.; BRUSS, M.L. Clinical biochemistry of domestic animals. 6. ed. San Diego: Academic Press, 2008.

KHAN, S.G.; KATIYAR, S.K.; AGARWAL, R.; MUKHTAR, $H$. Enhancement of antioxidant and phase II enzymes by oral feeding of green tea polyphenols in drinking water to $\mathrm{SKH}-1$ hairless mice: possible role in cancer chemoprevention.

Cancer Res., v.15, n.52(14), p.4050-2, 1992.
LIAO, S.; KAO, Y.H.; HIIPAKKA, R.A. Green tea: biochemical and biological basis for health benefits. Vitam. Horm., v.62, p.1-94, 2001.

MIURA, Y.; CHIBA, T.; TOMITA, I.; KOIZUMI, H.; MIURA, S.; UMEGAKI, K.; HARA, Y.; IKEDA, M.; TOMITA, T. Tea catechins prevent the development of atherosclerosis in apoprotein Edeficient mice. J. Nutr., v.131, p.27-32, 2001.

NIWATTISAIWONG, N.; LUO, X.X.; COVILLE, P.F.; WANWIMOLRUK, $S$. Effects of Chinese, Japanese and Western tea on hepatic P450 enzyme activities in rats. Drug Metabol Drug Interact., v.20, p.43-56, 2004. https://doi.org/10.1515/DMDI.2004.20.1-2.43 TEIXEIRA, L.G.; LAGES, P.C.; JASCOLKA, T.L.; AGUILAR, E.C.; SOARES, F.L.P.; PEREIRA, S.S.; BELTRÃO, N.R.M.; MATOSO, R.O.; NASCIMENTO, A.M.; CASTILHO, R.O.; LEITE, J.I.A. White tea (Camellia sinensis) extract reduces oxidative stress and triacylglycerols in obese mice. Ciênc. Tecnol. Aliment., v. 32, n.4, p.733-741, 2012. https://doi.org/10.1590/S0101-

20612012005000099

YANG, T.T.; KOO, M.W. Hypocholesterolemic effects of Chinese tea. Pharmacol. Res., v.35, p.505-512, 1997.

YANG, M.; YOSHIKAWA, M.; ARASHIDANI, K.; KAWAMOTO, T. Effects of green tea on carcinogen-induced hepatic CYP1As in C57BL/6 mice. Eur. J. Cancer Prev., v.12, p.391-395, 2003. https://doi.org/10.1006/phrs.1997.0176

Recebido para publicação em 16/08/2016 Revisado em 19/08/2016

Aceito em 20/08/2016 